\title{
SISTEMA DE IRRIGAÇÃO 4.0: UM ESTUDO DE CASO NA PRODUÇÃO DE MUDAS DE UVAS
}

\author{
Brendo Júnior Pereira Farias (UFCG) brendojr88@gmail.com \\ Jefferson Teixeira de Souza (UFCG) jefferson97ufcg@gmail.com \\ Daniel Augusto de Moura Pereira (UFCG) danielmoura@ufcg.edu.br \\ Rômulo Augusto Ventura Silva (UFCG) romuloaugusto@ufcg.edu.br \\ Tiago Gonçalves Pereira Araújo (UFCG) tiago.araujo@ufcg.edu.br
}

\begin{abstract}
Resumo
Atualmente as irrigações visam a busca pela máxima eficiência e precisão, recorrente da busca incessante pela redução dos desperdícios de recursos (sejam eles financeiros ou de recursos naturais, por exemplo). Neste sentido, a aplicação do conceito de indústria 4.0, inserida na agricultura de precisão, através dos princípios da Internet of Things (IoT), mostra inúmeras possibilidades de desenvolver dispositivos e sistemas que auxiliam na tomada de decisão do gestor, através de um feedback com mais confiabilidade (por meio de sensores) e, muitas vezes, apresentando um menor custo para o produtor, e consequentemente, o cliente final. Logo, o objetivo deste trabalho é mostrar o desenvolvimento de um dispositivo de controle aplicado a um sistema de irrigação de mudas de uvas, visando a gestão de recursos e IoT.
\end{abstract}

Palavras-Chaves: Agricultura 4.0; IoT; Gestão de recursos; Eficiência; Precisão.

\section{Introdução}

Os diferentes métodos de irrigação buscam a eficiência máxima na produção com o mínimo de água possível, com isso sendo um diferencial na irrigação por IoT, permitindo as possibilidades ao usuário de monitorar sua irrigação, receber informações de temperatura e umidade do solo, auxiliando a tomada de decisão a distância a partir de um smartphone, tablet ou algum outro equipamento mobile.

Uma das principais grandes áreas consumidoras de projetos baseados em IoT, é a agropecuária, ao mesmo tempo em que é um setor produtivo bastante evoluído, também apresenta um déficit quanto a aplicação de técnicas e tecnologias que promovam a melhoria, precisão e a automação de processos produtivos. (MUXITO et al., 2018)

Atualmente os sistemas de irrigação modernos são munidos com equipamentos microprocessados de alta tecnologia e precisão para monitorar e controlar diversas variáveis ambientais que garantem o desenvolvimento da cultura, porem são de alto custo e de difícil acesso ao pequeno agricultor (REIS, 2015). 
Os fundamentos modernos da agropecuária de precisão, segundo a literatura, surgiram em 1929, nos Estados Unidos, mas o ressurgimento e disseminação da técnica, ocorreram somente na década de 80, quando microcomputadores, sensores, atuadores e sistemas de rastreamento terrestres ou via satélite foram disponibilizados e possibilitaram a difusão dos conceitos, de determinação e gestão eficiente da variabilidade espaço-temporal (EMBRAPA, 2016).

Um sistema de irrigação bem projetado, além de garantir um melhor desenvolvimento de culturas diversas, também proporciona um maior aproveitamento dos insumos, contribuindo para um menor impacto ao meio ambiente, minimizando o desperdício de água e energia através do uso eficiente (REIS, 2015).

Com o avanço da tecnologia e disponibilidade de equipamentos acessíveis e úteis para o agricultor, tem-se a necessidade de utilizar formas sustentáveis e tecnológicas na agricultura, afim de aumentar a produtividade e reduzir custos.

Com isso o uso das tecnologias na agricultura vem-se intensificando cada vez mais e logo será inevitável não fazer o uso de tais equipamentos, que trazem respostas rápidas e precisas, para a palma da mão a distâncias imensas do plantio.

Pensando nisso esse trabalho tem como objetivo automatizar um sistema de irrigação de mudas de uvas destinadas a produção de vinho, utilizando dispositivos IoT, fazendo o monitoramento e controle via mobile

\section{Fundamentação teórica}

\subsection{Gestão de recursos e gerenciamento ambiental}

Para (ANTONIUS, 1999), de modo geral, o gerenciamento ambiental e consequentemente a gestão de recursos pode ser definida como a junção de sistemas e programas organizacionais que disponham de:

- Redução e controle dos impactos causados ao meio ambiente, perante o processo produtivo realizado;

- Cumprir as normais e leis ambientais;

- Avaliações e monitoramento dos parâmetros ambientais perante as normas;

- Redução ou eliminação de riscos ao homem e ao meio ambiente;

- Antecipação de questões ambientais susceptíveis a danos futuros; 
- Implementação de tecnologias limpas (clean Technologies) para a busca contínua de otimização de processos e preservação do meio ambiente afim de minimizar gastos (sejam eles financeiros, de matéria prima e etc).

\subsection{Controle hídrico e sua importância}

Segundo SILVA et al. (2016) o uso sem controle da água pode promover problemas na disponibilidade dos recursos hídricos, sendo a água um dos recursos naturais mais importantes na vida humana, é de grande importância abordar a discussão entre homem e uso da água.

A sobrevivência das gerações futuras depende diretamente das decisões que hoje estão sendo tomadas (SILVA et al., 2016)

"Podemos elaborar projetos de irrigação que possam ser executados na agricultura, com o intuito de reduzir o gasto desnecessário da água, já que as perdas podem chegar até 70\%" (IDOETA, 2015, p. 01).

\subsection{Controle hídrico na produção agrícola}

Tratando-se de produção agrícola, há muitas variáveis a se controlar, assim como inúmeras etapas, equipamentos e aspectos de gestão para se cuidar. Entre os sistemas de grande importância, se destaca a irrigação, capaz de fornecer um elemento imprescindível para a planta, especialmente em épocas pouco chuvosas. Contudo, manejar a água de irrigação não é uma tarefa simples, podendo ser estendido ou resumido como: definir quando irrigar e quanto de água aplicar. Assim, a capacidade de monitorar e alterar conscientemente os parâmetros dessa irrigação torna-se de grande importância (GUIMARÃES, 2011).

\subsection{Industria 4.0}

Segundo (ABDI), as primeiras revoluções da industrias (mais conhecidas como revoluções industriais) implicaram em determinados fatores. O primeiro fator deles, a produção em massa, o segundo, a criação das linhas de montagens, o terceiro, a eletricidade e consequentemente a T.I. (tecnologia da informação) que acarretou na briga ou corrida por novos métodos e tecnologias aplicadas a o meio de produção. A indústria 4.0 ou quarta revolução industrial implica na junção de meios e tecnologias que impliquem na união do meio físico, biológico e digital por meio da internet das coisas (IoT) onde se tem uma integração de todos os ambientes possíveis em busca da mais precisa execução de determinadas tarefas de forma autônoma assim otimizando-as e contendo o mínimo da intervenção humana em tais ações. 


\subsubsection{Princípios da indústria 4.0}

Segundo (SILVEIRA), para que haja a aplicação de algo relacionado a indústria 4.0 de forma efetiva, tal sistema ou dispositivo precisa portar determinados princípios que o caracteriza como de fato pertencente a um sistema ou dispositivo incluso na indústria 4.0 (princípios estes que a cada dia se tornam mais notáveis no mercado atual):

- Capacidade de operação em tempo real: Acolhimento e tratamento instantâneos de dados e informações capazes de permitir a tomada de decisão em tempo real.

- Virtualização: Cópia do ambiente real para que seja simulado em um ambiente virtual e consequentemente para a realização de testes antes da aplicação.

- Descentralização: A tomada de decisão não parte apenas de uma única pessoas e sim de acordo com resultados captados e captados pelo sistema em tempo real. Ou seja, não se tem apenas tomadas de decisões executadas pela vontade de um controlador e sim com o auxílio de determinadas ferramentas e meios inclusos no sistema e consequentemente no ambiente (sejam eles dados captados por sensores, por exemplo).

- Orientação a serviços: Aplicação e integração de arquiteturas de software direcionadas a internet das coisas (IoT);

- Modularidade: Capacidade de acoplamento ou desacoplamento de módulos no processo de produção afim de proporcionar flexibilidade para realizar diferentes tarefas nas ferramentas de produção que estão sendo integradas.

\subsection{Sistemas eletrônicos e autônomos}

Os sistemas eletrônicos e autônomos permitem uma grande melhoria na aplicação de projetos já realizados para determinado plantio. A introdução deste elemento em uma produção agrícola reduz, não só problemas de caráter humano de má operação, como também o consumo de insumos e o custo de produção. Ainda assim, a complexidade de se realizar o manejo da produção é tão elevada, que é inviável se projetar sistemas completamente autônomos (GUIMARÃES, 2011).

\section{Metodologia}

Este artigo pode ser caracterizado como de pesquisa experimental exploratória, pois, tem-se o acolhimento de um determinado dispositivo formulado a partir de pesquisas e que é usado como objeto de estudo e a partir dele é observado e explorado os fatores à cerca do conhecimento a ele aplicado e seu objetivo base (GERHARDT e TOLFO, 2009).

Um fator importante que deve ser levado em consideração dentre o processo metodológico da formulação do presente projeto é a aplicação do conceito base do Processo de Desenvolvimento 
de Produtos (mais conhecido como PDP), que no caso, foi-se realizada a investigação da necessidade de mercado, a busca por possíveis concorrentes e o público-alvo. Pois, não há fundamento formular algo sem um destino ou consumidor final (ROSENFELD et al., 2006).

A pesquisa foi desenvolvida na fazenda experimental do Centro de Desenvolvimento Sustentável do Semiárido (CDSA), da Universidade Federal de Campina Grande (UFCG) no ano de 2019. Foram distribuídos, numa green house, 24 vasos com mudas de uvas das variedades Syrah, Violeta, Touriga e Patrícia todas destinadas a produção de vinho, conforme ilustra a Figura 1.

Figura 1 - Montagem dos sistemas de irrigação e placas.

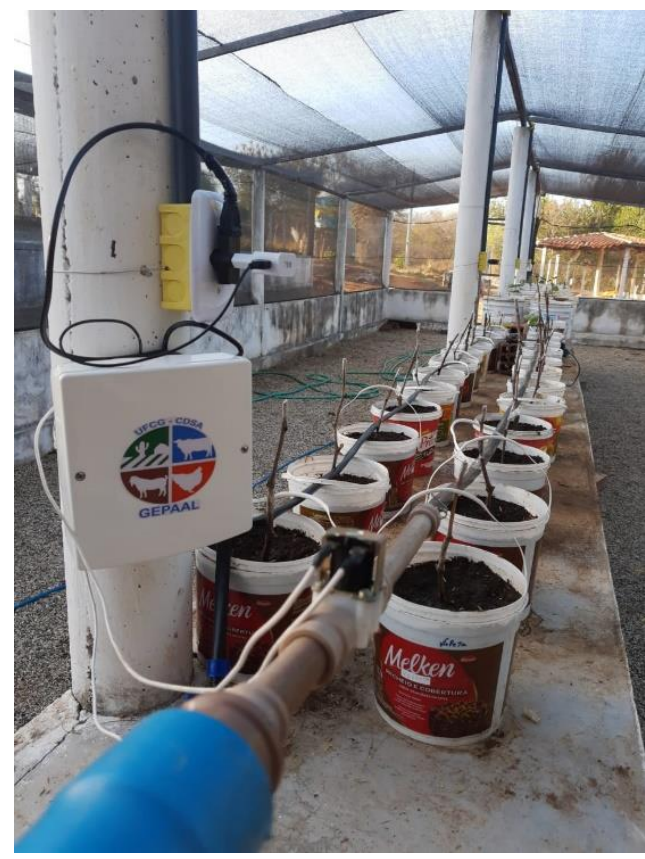

Fonte: Os autores (2019)

Os vasos foram organizados em duas linhas dispostas paralelamente. Foi utilizado uma fita de gotejadora de $16 \mathrm{~mm}$ com espaçamento de $20 \times 20 \mathrm{~cm}$ e a água utilizada para a irrigação era armazenada numa caixa d'água de 1000 litros, oriunda de sistema hidro-sanitário proveniente de lavatórios, máquina de lavar roupas, tanques e chuveiros.

O sistema de irrigação 4.0 foi instalado na greenhouse e o feedback dos dados era realizado via aplicativo Blynk. Nele, foi utilizado o recurso de projeto, para fazer os dashboards, assim tendo uma interface gráfica esteticamente mais atrativa e com rápida visualização (adotou-se o uso de dois medidores para fazer a visualização dos sensores - para o sensor de fluxo foi utilizado um display de valor para mostrar a quantidade em litros d'água gastos e para a válvula foi escolhido um botão para o acionamento da mesma. Além dos medidores e botão foi utilizado o recurso de gerar gráficos a partir dos dados dos sensores. Os gráficos gerados pelo aplicativo supracitado foram armazenados e gerados arquivos de texto (.CSV), sendo possível armazenar os dados nas 
nuvens, visualizar em navegadores e no aplicativo e baixar o arquivo para trabalhar off-line em planilhas Microsoft de Excel.

As conexões entre placas e o aplicativo só foi possível ser feita pela rede WI-FI, no caso deste estudo, foi utilizado um modem $3 \mathrm{G}$ com roteador WI-FI acoplado.

\section{Resultados e discussão}

O sistema controlador da irrigação era composto por duas placas NodeMCU embarcada e conectada a uma rede WI-FI (vide Figura 2), onde as mesmas serviam para o monitoramento e controle da umidade e temperatura do solo e outra placa para acionar a válvula solenoide, afim de fazer a abertura e fechamento da água para a irrigação, e um sensor de fluxo para quantificar o gasto diário da água, tudo isso conectadas a uma rede WI-FI.

Figura 2 - Circuitos da estação 1 e 2 em fase de prototipagem

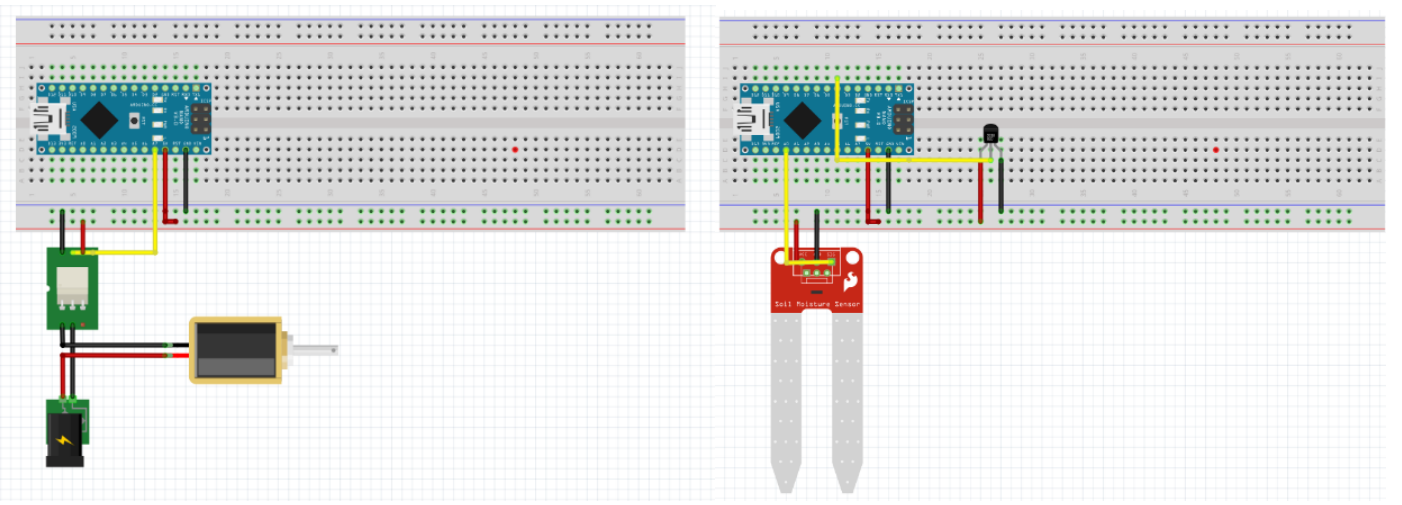

Fonte: Tinkercad (2020)

A placa que fazia o monitoramento das variáveis climáticas foi instalada em nível dos vasos e utilizado dois sensores, um de umidade do solo (higrômetro) e outro de temperatura do solo (termopar tipo T), fazendo a coleta dos dados dos sensores e enviando para o aplicativo, gerenciado todas as informações do sistema instalado via mobile.

A outra placa ficava responsável pelo o acionamento de um modulo relé, que energizava a válvula, fazendo com que ela abrisse ou fechasse. Neste estudo foi utilizada uma válvula solenoide (normalmente fechada) de $1 / 2$ polegada e um sensor de fluxo, ambos acoplados a mangueira de irrigação, nesse sentido o sensor de fluxo mostra o consumo de água assim que a válvula é acionada.

Os vasos foram organizados em duas linhas dispostas paralelamente, foi utilizado uma fita de gotejadora de $16 \mathrm{~mm}$ com espaçamento de $20 \times 20 \mathrm{~cm}$, a água utilizada era liberada a partir do 
momento em que era acionado um botão (liga/desliga) via aplicativo, os condicionantes para tal tomada de decisão eram os valores dos sensores, que eram enviados a cada 30 minutos pelas placas para o aplicativo e permitia o monitoramento e controle da irrigação, conforme ilustra a Figura 3.

Figura 3 - Dashboards e gráficos gerados a partir dos dados coletados pelos sensores e botão de acionamento.

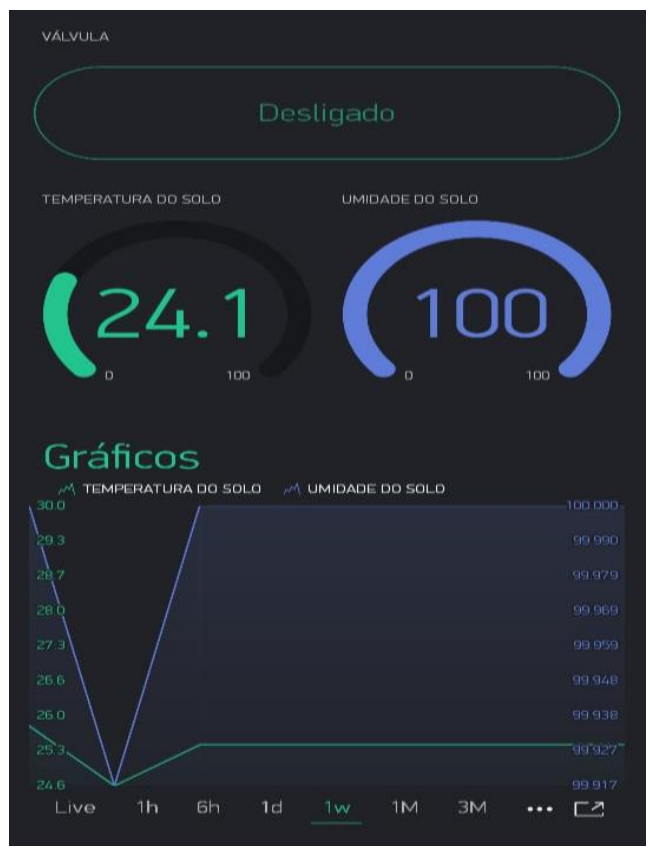

Fonte: Adaptado do Software Blink (2020)

Os valores de umidade do solo eram mantidos sempre entre $60 \%$ e $95 \%$, o que garantia umidade suficiente para o bom desenvolvimento das plantas. A temperatura do solo também era controlada entre $19^{\circ} \mathrm{C}$ até no máximo $35^{\circ} \mathrm{C}$, desta forma era acionado ou fechada a válvula solenoide. Caso houvesse uma temperatura e umidade do solo não desejadas, o aplicativo era responsável por enviar uma notificação no dispositivo no qual estivesse instalado, avisando que era necessário ativar a irrigação remotamente.

Com base nas informações geradas pelos sensores, pode-se notar neste estudo que a umidade e temperatura do solo tinham uma mudança brusca em seus valores a partir das 14:00 horas, horário que, comumente, em que o sistema de irrigação era acionado pelo aplicativo, realizando a abertura da válvula, com o objetivo de manter a temperatura e umidade entre faixas de temperatura e umidade estabelecidos pelos manuais de cultivo de uvas. 
O objetivo deste trabalho foi desenvolver um sistema de irrigação 4.0 em uma green house de mudas de uvas. O sistema aqui desenvolvido trouxe benefícios como economia de água durante a rega, controle de umidade e temperatura do solo e feedback em tempo real do statos quo de alguns parâmetros climáticos daquela green house, o que possibilitou uma tomada de decisão mais eficiente e eficaz, e que resultou numa maior qualidade das mudas.

Notou-se ainda que sistemas de irrigação com dispositivos IoT podem ser muito eficientes, além de possibilitar maior controle sobre a irrigação, minimizando erros humanos, preservando recursos naturais valiosos, como a água, além de ser inovadora no que diz respeito a ser utilizada e monitorada com um simples acesso à internet pelo seu dispositivo móvel. 


\section{REFERÊNCIAS}

ABDI. Industria 4.0. industria40.gov.b. Disponivel em: <http://www.industria40.gov.br/\#>. Acesso em: 15 Janeiro 2020.

ANTONIUS, P.A.J. A exploração dos recursos naturais face à sustentabilidade e gestão ambiental: uma reflexão teórico-conceitual. Belém - PA: NAEA, 1999.

EMBRAPA, Empresa Brasileira de Pesquisa Agropecuária. Automação e Agricultura de

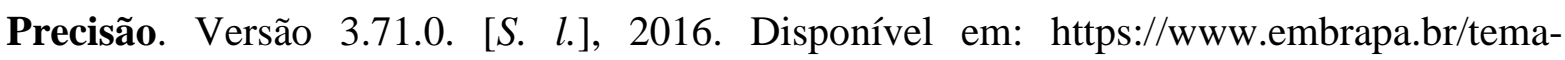
mecanizacao-e-agricultura-de-precisao/nota-tecnica. Acesso em: 6 nov. 2019.

GERHARDT, T.; TOLFO, D. MÉTODOS DE PESQUISA. 1º ed. UFRG: [s.n.], 2009.

GUIMARÃES, Vinícius Galvão. Automação e monitoramentoremoto de sistema de irrigação na agricultura. 2011.91 p. Trabalho de conclusão de curso (Curso de Graduação em Engenharia de Controle e Automação) - UNIVERSIDADE DE BRASILIA Faculdade de Tecnologia, Brasília, 2011.

IDOETA, P.A. A agricultura é vilã ou vítima na crise hídrica? bbc, 2015. Disponível em: <http://www.bbc.com/portuguese/noticias/2015/03/150302_agua_agricultura_pai>. Acesso em: 26 out. 2019 .

MUXITO, Ezequiel Manuel et al. IoT na Agricultura - Automação de Pivôs e Canais de Irrigação com Arduíno e Webservice. III Congresso internacional Adventista de Tecnologia (CIAT), [s. l.], 2018. E-book.

REIS, J. S. Sistema de controle aplicado à automação de irrigação agrícola. 73p. Monografia (Graduação) - Tecnologia em Automação Industrial, Universidade Tecnológica Federal do Paraná, 2015.

ROZENFELD, H.; FORCELLINI, F.A.; AMARAL, D.C.; TOLEDO, J.C.; SILVA, S.L.;

SILVA, Eliézer Cláudio Ribeiro et al. AGRICULTURA IRRIGADA NO CONTEXTO AMAZÔNICO: UMA ABORDAGEM SISTEMÁTICA DO USO DA ÁGUA EM UMA HORTICULTURA NO MUNICÍPIO DE ALTAMIRA-PA. Revista Internacional de ciências , [s. l.], v. 6, ed. 1, 2016. DOI 10.12957/ric.2016.22926. Disponível em: https://www.e-publicacoes.uerj.br/index.php/ric/article/view/22926. Acesso em: 5 nov. 2019. SILVEIRA, C. O Que é Indústria 4.0 e Como Ela Vai Impactar o Mundo. CitiSystems. Disponivel em: <https://www.citisystems.com.br/industria-4-0/>. Acesso em: 15 Janeiro 2020. 